\title{
Documentation of the Crime Scene
}

\author{
Mr.Sc.Besim Arifi, PhD Cand. \\ European University of Tirana \\ besiarifi@hotmail.com
}

\begin{abstract}
Documentation of the scene is one of the most important actions of the investigative group, which performs the examination of the scene. Documentation in itself includes: Taking notes, drawing and photographic team of the site inspection to the crime scene during phase taking notes must pay special attention to this stage, because it includes very important information for the investigation of the crime scene. Based on these information becomes final report on the case, so we can say that taking notes is of particular importance. Another important action is also the sketch. Mapping shows the drawing of the scene and all evidence was found there. Compiler of the sketch doesn't minds to be definitely professional any painter or designer. It should be a good compiler which presents in detail all the information necessary to include net. This information will be used for testimony in court and to clarify the situation in the scene in case of reconstructions. Photographs of the crime scene investigation is a very important move which reflects the real image of the scene or any part of his and any evidence which has been inserted into focus photography.
\end{abstract}

Keywords: Documentation, taking notes, drawings, blueprints, photographs, scene

\section{Documentin Crime Scene}

For a case to have success and the right result, both in terms of quality, which will be displayed after a working professional investigation group, both in terms of understanding how best by those who will have the opportunity see, have become a professional documentation, clear, understandable and all sufficient data.

To achieve the result satisfactory and demanding, it is necessary to have a record fair and professional, in order that all work performed and the procedures followed by the investigation team, reflected very clearly and be accessible to all those who consider the case at a later stage.

Documentation of the scene includes:

- $\quad$ Taking Notes

- $\quad$ Sketch

- $\quad$ Photography

- $\quad$ Taking Notes

One of the main actions and more important investigators of the scene is taking notes. Taking notes is done for many reasons. One of the main reasons, why should it be asked, is that they should be available to all case and then, when the investigator or the court requires something, entries must be ready and similar actions were taken at the scene and with all other data, such as the scene, as well as traces and physical evidence found there.

Taking notes begins upon receipt of the call for the given case noted: time, date, source of the information was, instructions are provided for storing the scene.

Further extended the composition of the investigation team, responsible officials find there and the time of arrival at the scene. It should also be noticed and all actions of the inquiry regarding the examination of the scene until its conclusion. 
The focus is on objects, to track and to the material evidence, distinguishing it traces or evidence that is relevant materials, related to the event, from what can be found randomly on the scene.

Here's how the notes should be a crime scene investigator:

1. Notes must be accurate and sorted chronologically;

2. The entries should describe step by step all the action;

3. The entries must be completed and harmonized;

4. Notes should be well written and understandable;

5. It must be noted the unusual things such as blood, a light that has been raging, etc .;Hetuesi takes notes should be, as much as possible, specific mark even the most "fine" as $20 \mathrm{~cm}$ below stairs of the house, on the ground floor is found .... etc.

6. Other records such as case number, camcorder, film negatives, etc., should never be left without mark. They may be listed in any other country but here it is worth noted;

7. Determination and location of the route or test materials done in conjunction with a stationary object such as wall, pillar electricity, etc.1

The investigator had come on the scene; the officer should initially contact the first on the scene and has secured his victim, witnesses. In this way, he will be informed of certain data of the scene which will probably be needed later. All these should be noted carefully.

In the notes of the scene investigators must be included:

- The date and time when the case is reported to the police;

- Type of crime;

- Location of the scene and its description;

- Name of the person who ordered / requested location-viewing;

- The names of all persons, police officers, witnesses, investigators, specialized personnel to the scene.

- Names of officers photograph, shooting with the camera, make sketch, take fingerprints, seek and obtain clues and material evidence;

- atmospheric and lighting conditions at the time of inspection;

- The first description of the scene, including the condition of the victim at the time the investigation team has arrived;

- The location of any trace or evidence material that is found and by whom is found, the search results of fingerprints and other trace evidence;

- Description of the exact location of the scene, surrounding houses or buildings;

- Description of the correct entry and exit of the scene, a description of the house, number of rooms, windows;

- Description of the external scene: land, planted field, the ground muddy, ground paved with asphalt, tiles, etc .;

- The time of completion of the examination of the scene;

- In the notes given no conclusions, but what can be seen in it.

1 prof. dr. Luan VELIQOTI,(interview)Tiranë, maj 2011. 
Whether through photography "write by the light" in the record write only what look. Conclusions belonging to other investigative actions as: expertise, knowledge, experiment etc.

\section{Mapping}

Just picture is not enough to fix the scene. Since scene appear better and more accurately, he should have the sketch. So, sketches and picture complement each other and both represent scene correctly and adequately. Outline clarifies scene appearance and makes it easy to understand. It is therefore important that the crime scene investigator to do a good outline and easily understandable.

Compiler sketch should not be necessarily a good painter or designer, but everything that represents the outline should be clear even to those who were not at the scene and did not see it. So I have a drawing simple, understandable that presented the appearance of the scene.

In pictures look even objects that "do not want" to see, because they cannot share or remove without interfering in it, while at present only drawing objects that we need and we want to present.

Well sketches, it helps investigators, courts and others to recall things. Also it serves quite well, compared to photography, even when we have the opportunity to see cars or any other view of the scene. This can be used by investigators during the questioning of witnesses or victims.

There are two types of drawings: the general and detailed generalized sketches done on the spot, it is a simple drawing, freehand and all the other features that accompany it, while detailed sketches done in the office with technical means or computer. Both sketches enter in the case file and stored there.

Always sketches done in the angle 90 degrees and is called two-dimensional sketch, unlike it three dimensional made at different angles and in other cases (of mass graves, sketches wells etc.).

Completes sketches and notes very well pictures of the scene.

\section{The information included in sketch}

In the sketch should be presented with all the information that identifies the case. They are: the case number, the name of the victim, the name of the suspect, the date and time when the event occurred, the date and time when sketches, location, name of the person who made the sketch, the degree of proportionality, whether it is used or no, (a legend would help its reader), spatial orientation, fixed points where measurements were made, the numbers of evidence etc ${ }^{1}$.

\section{Equipment}

Equipment used in the preparation of the outline is simple including: white paper, pencils technique or simple tools geometric, ruler, compass, triangle, rectangle, etc., and if sketches done with computers then used different software for drawing drawings.

\section{Types of sketches}

Depending on the scene, we have several types' sketches and methods by which they are made. Types of drawings are: Two-dimensional and three-dimensional sketches.

1 Criminal Investigations,Charles R.SWANSON, Neil C. CHAMELIN, Leonard TERRITO, 7th, ed .2000, fq. 57. 
Dimensional drawings used in almost all cases when dealing with surfaces that appear only the width and length of the terrain scene. These include countries in the event of open, closed, in cars etc.

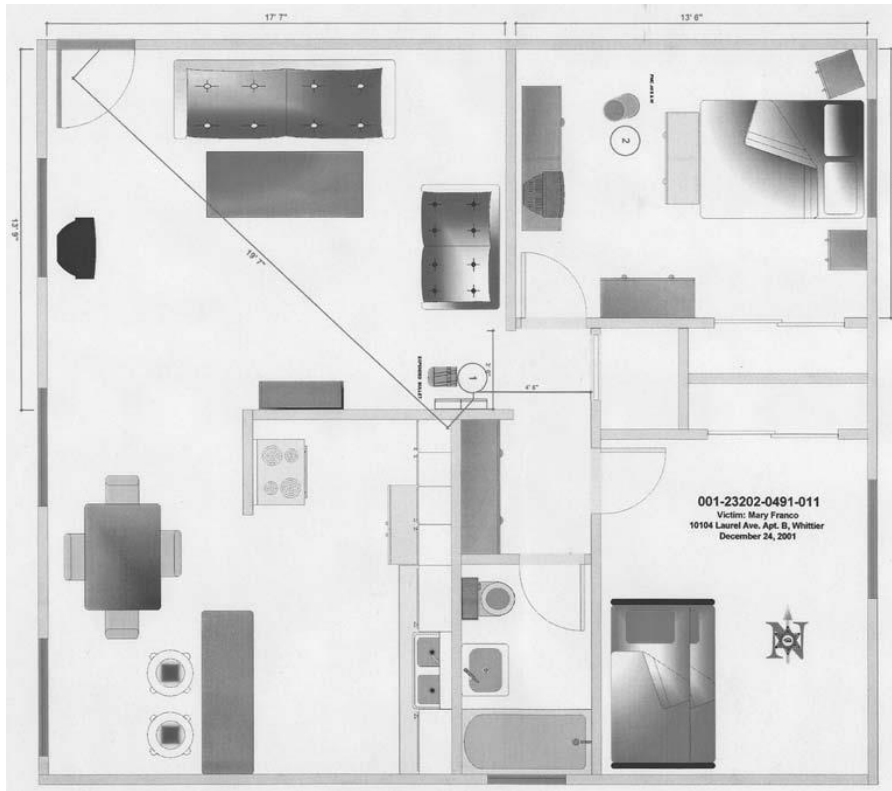

Fig.1 Two-dimensional sketch (foto nga: http://crimescene_pictures.jpg)

A three-dimensional drawings used in all cases, when the field of the scene is the width, length and depth. These cases have in mass graves, different wells, cars etc. In these cases different templates performed during the reconstruction of the crime scene or during the presentation to the court.

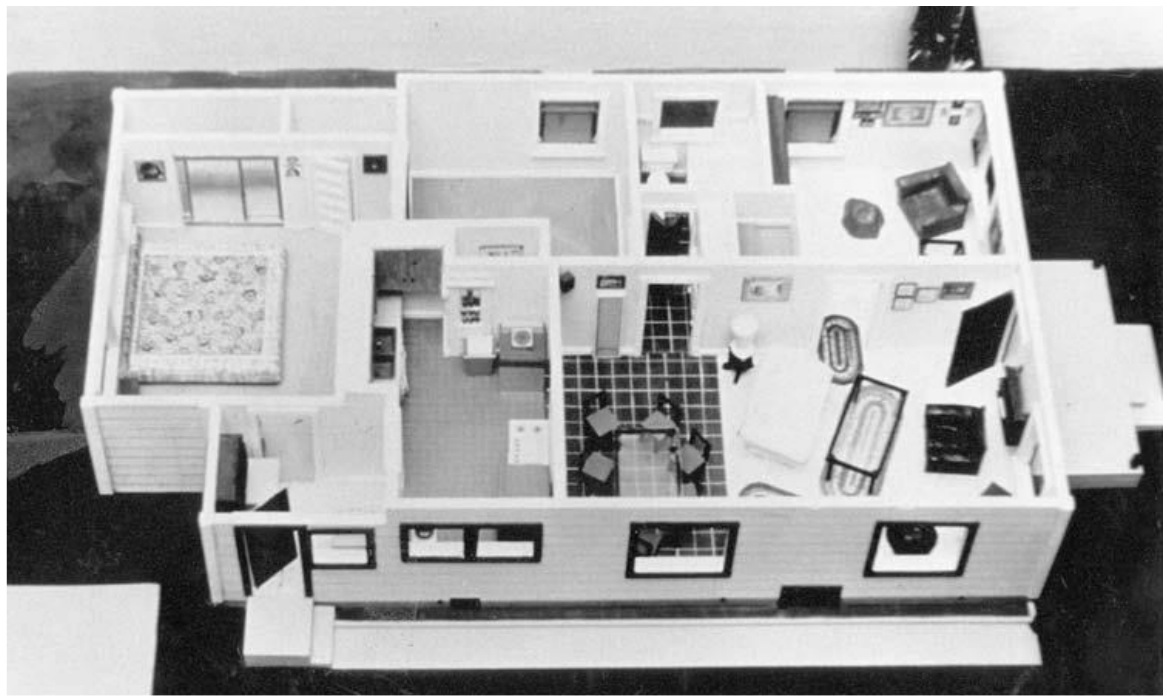

Fig.2 Three-dimensional mock-up of one of the crime scenes from the infamous Hillside Strangler Case in Los Angeles, California.) 


\section{Methods of drawing}

To realize charts used three methods:

-The Method coordination;

-The Method triangular;

-The Method cruise.

Coordination method has at least two fixed points of which measured all traces and physical evidence found at the scene. This method can also be used basic line, this line which imagined between the scenes and starting from that line, measure all the evidence on both sides. This method is suitable outdoors.

Triangular method has at least two fixed points of which track and measure all material evidence at the scene. This method is used outdoors and in those places where we encounter difficulties finding a fixed point: in the field, away from the road, in cases of traffic accidents etc.

Cruise Method - This method is used in confined spaces. Here, the walls of the rooms appear to spread. The rooms have expansive roof along with one of its walls

\section{SECENE PHOTOGRAPHY}

The word: "a picture is worth a thousand words" applies especially to photograph the scene. Capture or "recording" permanent crime scene is a very important action of the investigative group in the processing and examination of the scene. It is very important that before any other action, including: touch, movement, screening etc, It is photographing everything they found at the scene, which is estimated to trace or proof material.

No subject should not move, before he is photographed from all angles necessary. For all of this to have its effect during the trial should be made as many pictures as possible. We must not forget that pictures can help the prosecutor at the court hearings, the judge, police experts etc.

It is the duty of every crime scene investigator who, once they get there after receiving initial information, start with general or orientation picture of the scene. The investigator then must continue to focus in the important points of the country example: center of the scene, to connect the tracks or exhibits through photography, etc. sequential pictures.

A special focus should be placed, given the nature of the crime, in order to present the elements of the offense. Particular attention should be paid:

Exteriors of the house, the car;

- Communications them among each other;

- Route, access points outside and inside;

- Point exit inside and outside;

- Conditions of the scene;

- Things that are left at the scene;

- Evidence as hair, synthetic fibers, remnants (butts) cigarette, fingerprints, tool marks, shoe tracks, tire tracks, etc.. 
Special importance should be given the restrictive photos of the scene. They should be made so that, when seen, are listed in a logical manner making a real orientation of the country. Photos restrictive are:

\section{a.Photography with remote shooting (indicative)}

This picture is done by including in it, all the space of the scene (if possible), so that when this photograph shows, the impression that you are

seeing the scene nearby. This picture shows the position of the scene compared to other surrounding objects such as buildings, objects or objects ${ }^{1}$. This picture is made in the eye distance, six meters away

\section{b.Photography to shooting medium (general)}

This picture is made so that in the related areas of the scene to the photographed areas. It also enables the connection of trails and exhibits between each other. This picture becomes distance from three to six meters, in order to have a clear view and its reading.

\section{c.Picture by shooting near (the object close)}

This pictures are made in order to be introduced in all the sights, which could not be introduced in the middle photography shooting and remote. This photo is taken at a distance of one or two meters. Since this picture done by a small distance, they can be seen in great detail which does not appear in the previous pictures.

\section{d. Picture scalable}

This pictures is done when, close to the tracks and physical evidence found at the scene, set the unit of measurement such as rulers, meter etc. So, taking pictures scalable, show how many times has increased or decreased the object photographed ${ }^{2}$.

\section{WHAT WHE NEED TO SEE IN THE FIELD OF SIGHTING MARK}

During photographing the traces and material evidence at the scene, placed close to their units, in order to show the real size. Setting the measuring unit as a meter tape, ruler, etc. It allows the photographer to determine the real size and scale of its reduction. Care should be taken when displaying measurement units, not damaged track or exhibits.

In order to eliminate the objection that sometimes made pictures yardstick, then the photos should be made once without a measure of another time with the measure.

\footnotetext{
1 Prof.dr.Skënder Begeja,Kriminalistika,Vëllimi i I.2001,Tirane,fq.80

2 Prof.ass.dr.Luan VELIQOTI,Fotografia Kriminalistike,Tiranë,2001,fq.138 
To comply with general standards used for review of the reliability and credibility of photography, be aware that:

- $\quad$ representation to be accurate;

- to no distortions;

- $\quad$ materials and connectivity;

- impartiality or fairness.

Also, during the shooting of the scene, one that photographs should be caution, control the movements you do, in order not to damage the picture. So a near static, allows a small movement or eliminate it all and, thus, will have a clear picture of which would have a good view. You should know that even breathing, heart and work of uncontrolled movements, caused by improper maintenance of the camera, have an impact on its stability and the quality of photography.

If photographed details, trace and material evidence, then, camera and tripod fixed to shutter button is propelled by spring wire. This is to avoid any vibration thereof, and to ensure maximum focus and clarity.

\section{Literature}

[1] Criminal Investigations, Charles R.SWANSON, Neil C. CHAMELIN, Leonard TERRITO

[2] Hillside Strangler Case in Los Angeles, California.)

[3] http://crimescene_pictures.jpg

[4] prof. dr. Luan VELIQOTI,(interview)Tiranë, maj 2011.

[5] Prof.ass.dr.Luan VELIQOTI,Fotografia Kriminalistike

[6] Prof.dr.Skënder Begeja,Kriminalistika,Vëllimi i । 